\title{
Sealing performance analysis of composite gaskets made of silicone rubber filled with ramie natural fibers
}

\author{
W. S. Widodo ${ }^{1,2^{*}}$, R. Soenoko ${ }^{1}$, M. A Choiron ${ }^{1}$, A. A Sonief ${ }^{1}$ \\ ${ }^{1}$ Faculty of Engineering, Brawijaya University, Malang, Indonesia. \\ *Email: saptowi@student.ub.ac.id \\ Phone: +6289679914226; Fax: +6289679914226 \\ ${ }^{2}$ Fakulti Kejuruteraan Pembuatan, Universiti Teknikal Malaysia Melaka, \\ Hang Tuah Jaya, Durian Tunggal, Melaka, Malaysia
}

\begin{abstract}
Silicon rubber gaskets are commonly used in many industries for low pressure sealing conditions only. The research studies about the sealing performance improvement of a novel composite gasket made of the silicone rubber filled with ramie natural fibers in a bolted joint connection. In this research the sample of gasket consists of 4 different types of gasket i.e. a pure silicone rubber gasket and the silicone rubber composite gasket with 1,2 and 3 layers of ramie fiber woven. The gaskets are tested using a water pressure testing equipment with a variation of internal fluid pressure and difference torques at 8 N.m, 12 N.m, 16 N.m and 20 N.m. The sealing performance is measured based on the maximum fluid pressure that can be hold by the gaskets before the fluid leaking occurred. The results show that the silicone rubber composite gaskets have better sealing performance comparing with the pure silicone rubber gaskets where the silicon rubber gaskets capable to hold the internal fluid pressure until around 5 times rather than pure silicon rubber gaskets $(0.17 \mathrm{MPa}$ comparing with 0.90 $\mathrm{MPa})$. On the other hand the sealing performance of the composite gasket with 3 layers is almost 2 times better than the composite gasket with 1 layer and around 1.5 times better than the composite gasket with 2 layer of fiber woven.
\end{abstract}

Keywords: Silicone rubber; sealing performance; ramie natural fibers; bolted joint.

\section{INTRODUCTION}

Seals are very important devices to prevent fluid leaks in a bolted joint connection [1]. Silicone rubbers have been widely used as seal elements or gaskets and play important roles in piping connections in some industries such as food industries, automotive industries, oil and gas industries, etc. However silicone rubbers can be applied in low pressure environments only [2]. Figure 1 shows a general gasket installation in a bolted joint connection. 


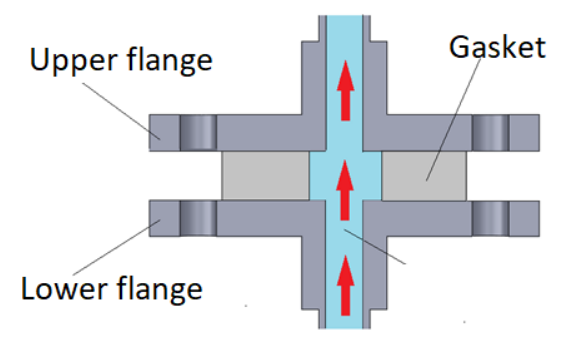

Figure 1. General gasket installation in a bolted joint connection.

Some researchers investigated about the silicone rubber characteristics/ properties and the effects of the fibers in the silicone rubber material properties for many applications [3-13]. Other studies investigated about the sealing performance of the gasket using diferent materials [14-18]. Some researchers used a finite element (FE) simulation method to evaluate the sealing performance of the gasket [15-22] while the other researchers used an experimental work to analyse the sealing performance $[1,3,7,14,15]$. Noshirwaan et al. [12] review the characteristics and applications of various gasket made of metals, non-metals, polymers and hybrids while Layth et al. [13] provide a comprehensive review of the natural fiber reinforced polymer composites (NFPC) and their applications. Noshirwaan et al. stated that as a gasket application the silicon rubber is a material of choice for moderate strength and elasticity while Layth et al. concluded that chemical treatment of the natural fibers improved the physico-mechanical and thermochemical properties of the NFPCs. Effects of the additional fiber such as palm fiber, or woven fabrics to improve the mechanical properties of composites also conducted by some researchers [23-25], which show that these materials could improve the properties of the composites significantly.

Persson and Yang [1] firstly introduced a theory relates to leak-rate of seals based on the percolation theory and contact mechanics theory. Persson and Yang analysed the role of surface roughness in the interface between a rubber and a hard counter surface at different magnifications. Yang et al. [3] investigated the fabric reinforced rubber composites of tubular seals using finite element simulation and experimental work. Yang et al. concluded that the existence of the fabric increases the compression force and improved the sealing performance of the tubular rubber seal. Yin et al. [4] studied about carbon fibers lattice structure filled with silicone rubber and found that this type of composite experienced higher stress level region which is very good in term of energy absorption and good sealing performance. Wen et al. [5] studied characteristics of nano-hydroxyapatite/silicone rubber composite for medical application, while Wang et al. [6] used carbon fiber combined with silicone peroxide as silicone rubber reinforcement. Meunier et al. [7] performed mechanical characterization which consists of tensile, pure shear, compression, plain strain compression and numerical modeling for an unfilled silicone rubber. Lorenz and Persson [14] experimentally investigate the leak rate of rubber seals and compare the results with the percolation theory and contact mechanics theory.

Some researchers focused on the sealing performance of gaskets made from different materials. Choiron et al. [22] evaluated the effects of contact area to sealing performance of the corrugated metal gasket based on FE simulation and helium leak test experiment. It was found that higher contact area and contact stress between flanges and gasket provides better sealing performance of the corrugated metal gasket. Nurhadianto et al. [19-20], Karohika et 
al. [21] and Choiron et al. [22] investigated the effects of contact area and contact stresses in the sealing performance of the corrugated metal gasket. Choiron et al. [15] used a water pressure test equipment to evaluate the sealing performance of the gasket. Choiron et al. [22] also used a helium leakage equipment to analyse the sealing performance of the metal corrugated gasket.

Through a comprehensive literature review shows that there are no scientific studies reported on the silicone rubber composite filled with natural fibers and still there is a gap in the silicone rubber composite filled with natural fibers research field especially for gasket applications. This study will be investigating the sealing performance improvement of the silicone rubber gasket in the bolted joint connection by addition of ramie natural fibers.

\section{METHODS AND MATERIALS}

\section{Materials}

In this study, the composite gaskets were made of the acetic silicone rubber filled with the ramie (Boehmeria nivea) natural fiber woven and flanges were made of stainless steel SUS304. Figure 2 a depicts the ramie natural fiber woven which is used in the research while Figure $2 b$ shows the orientation angle of the ramie fiber woven.

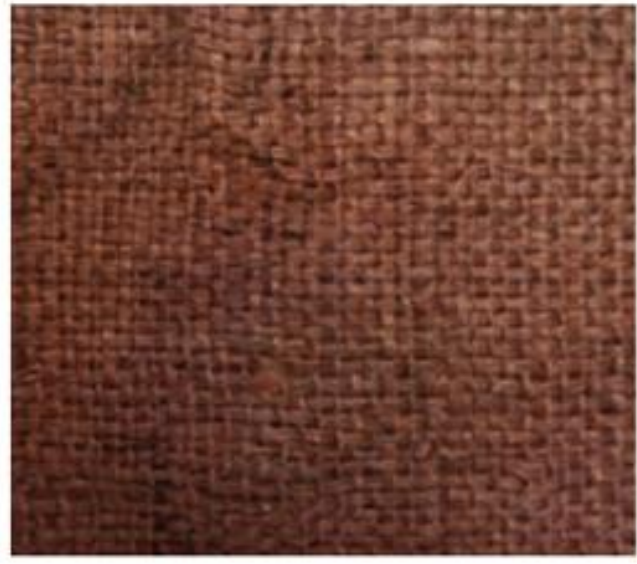

(a)

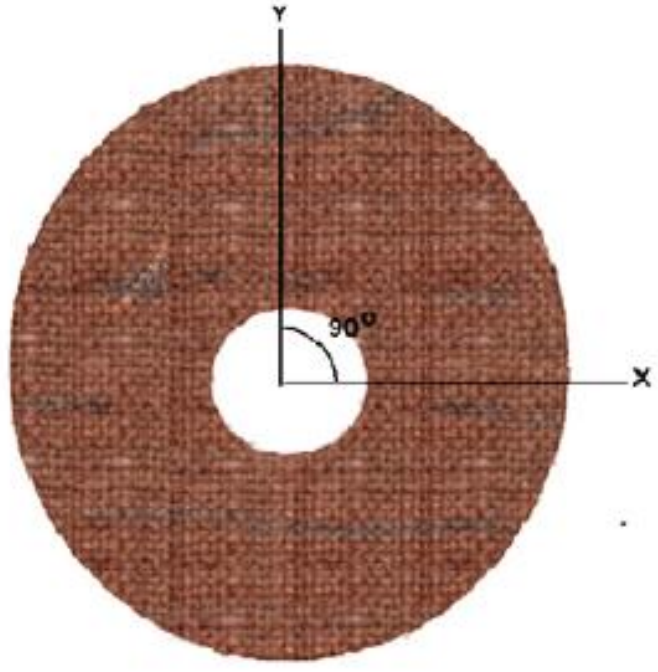

(b)

Figure 2. (a) Ramie natural fiber wofen and (b) orientation angle of the ramie fiber.

Table 1 shows the ramie fiber properties. The average thickness of the ramie fiber woven is $2.3 \mathrm{~mm}$. Table 2 shows the material properties of SUS304 while Table 3 presents the properties of the acetic silicone used in the research. 
Table 1. Material properties of Boehmeria nivea/ramie [11].

\begin{tabular}{ll}
\hline Property (unit) & Value \\
\hline Density (g/cm3) & 1.5 \\
Tensile strength (MPa) & 500 \\
Young's modulus (GPa) & 44 \\
Elongation at break (\%) & 2 \\
\hline
\end{tabular}

Table 2. Material properties of SUS304 [26].

\begin{tabular}{ll}
\hline Property (unit) & Value \\
\hline Tensile Strength, Ultimate (MPa) & 505 \\
Tensile Strength, Yield (MPa) & 215 \\
Modulus of Elasticity (GPa) & $193-200$ \\
Elongation at break (\%) & $70 \%$ \\
Poisson's Ratio & 0.29 \\
Shear Modulus (GPa) & 86 \\
\hline
\end{tabular}

Table 3. Material properties of Acetic Silicone [27].

\begin{tabular}{ll}
\hline Property (unit) & Value \\
\hline Specific gravity (ISO 2811-1)(g/ml) & 95 \\
Flow resistance (ISO 7390), (mm) & $\leq 2$ \\
Skin formation time (min) & 15 \\
Curing rate (days / 5mm) & $2-3$ \\
Application temperature $\left({ }^{\circ} \mathrm{C}\right)$ & +5 to +40 \\
Shore A hardness (DIN 53505) & 16 \\
Elastic recovery $(\%)$ & $>80$ \\
Temperature Resistance $\left({ }^{\circ} \mathrm{C}\right)$ & -30 to +120 \\
Modulus at $100 \%$ elongation $(\mathrm{N} / \mathrm{mm} 2)$ & $\leq 0,3$ \\
Elongation at break $(\%)$ & 130 \\
\hline
\end{tabular}

The mass of silicone rubber composite gasket filled with ramie fiber, $\mathrm{m}$, can be define as:

$$
\mathrm{m}=\rho_{s} v_{s}+\rho_{r} v_{r}
$$

where $\rho_{\mathrm{s}}$ and $\mathrm{v}_{\mathrm{s}}$ are density and mass of the silicone rubber, while $\rho_{\mathrm{r}}$ and $\mathrm{v}_{\mathrm{r}}$ are density and mass of the ramie fiber woven. 


\section{Gasket and Flange Geometry}

Figure 3 to Figure 5 show the details dimension of the gaskets and flanges as well as the real models that have been produced. The diameter of the gasket is referring to the $50 \mathrm{~A}$ standard on JIS B 2404.

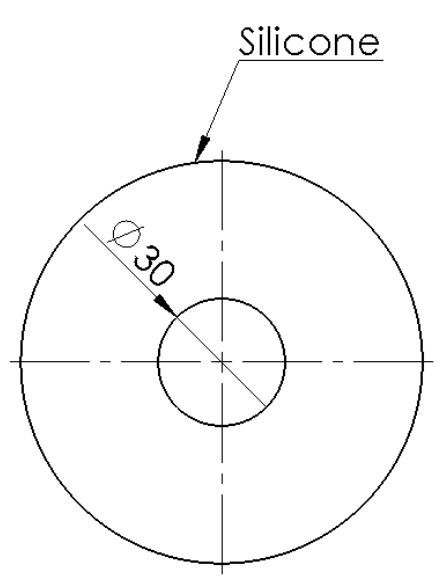

(a)

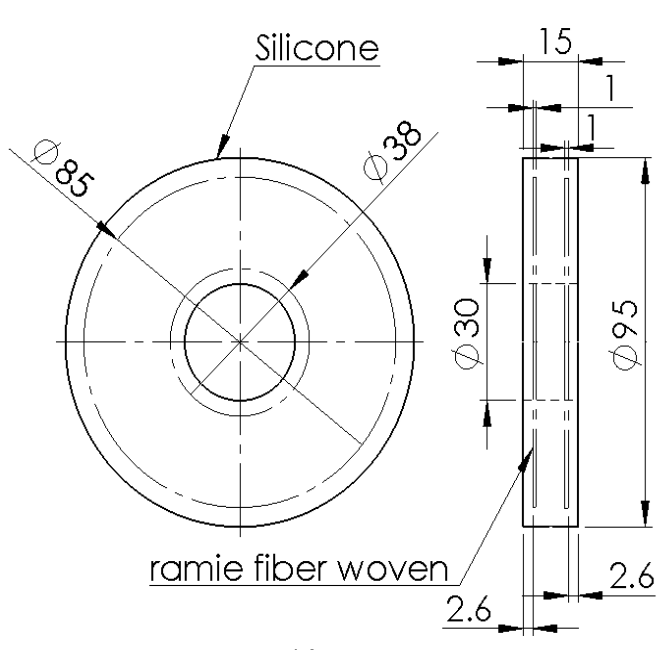

(c)

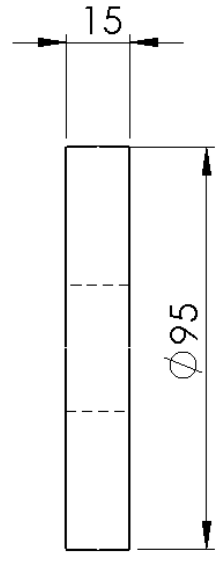

Figure 3. Gaskets dimensions (a) gasket type 1; (b) gasket type 2; (c) gasket type 3 and; (d) gasket type 4 .

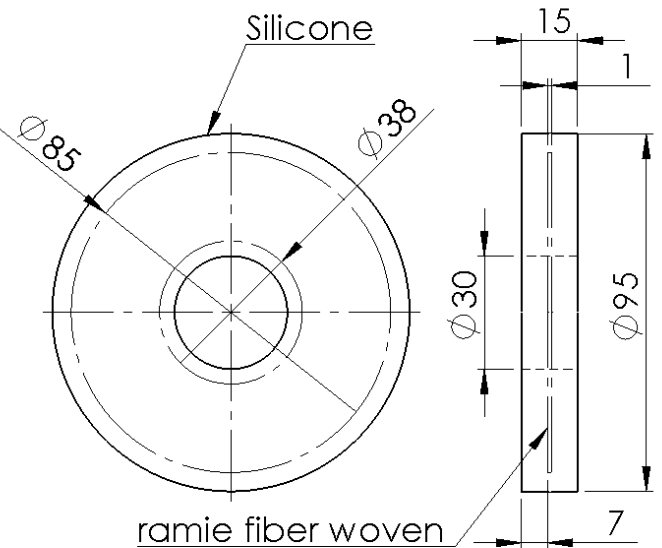

(b)

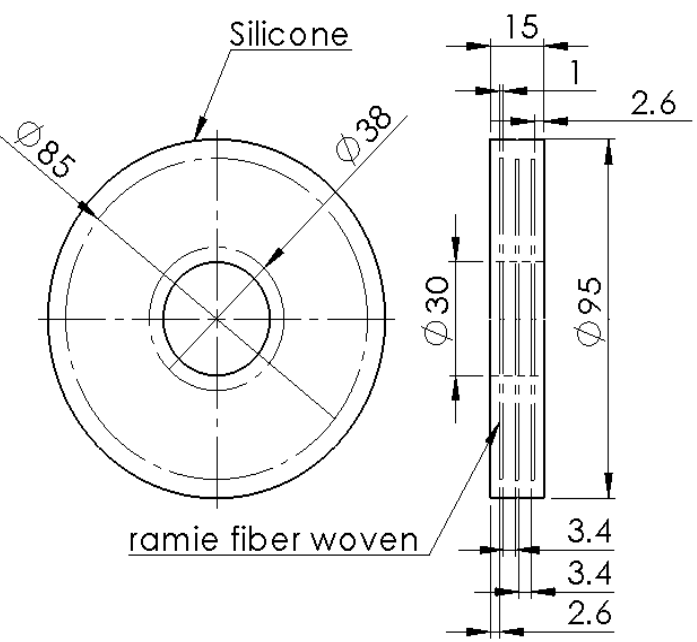

(d) 


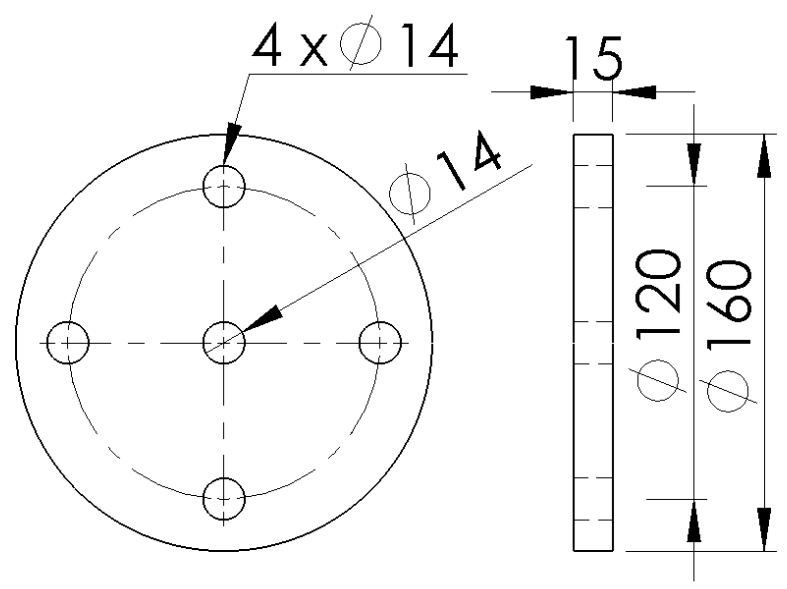

Figure 4. Stainless steel flange dimensions.
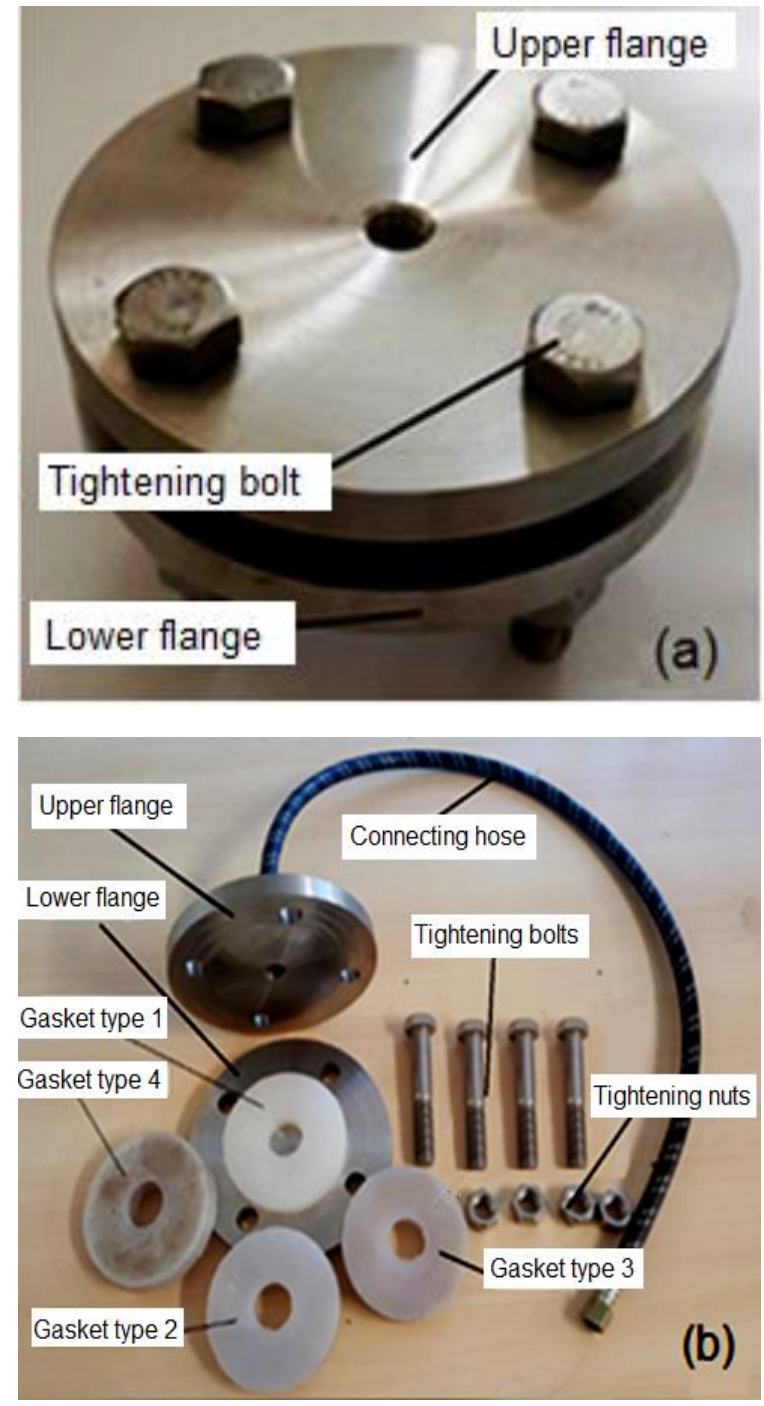

Figure 5. (a) gasket-flanges full assembly and; (b) gasket flanges assembly components. 


\section{Gasket Manufacturing}

The gaskets were made by a gravity molding process using a simple mold. The curing process occurred in a room temperature and at an atmospheric pressure for around 72 hours to ensure that the internal region of the gasket perfectly cured. Figure 6 shows a sample of the silicone rubber gasket with a single layer of ramie fiber woven.

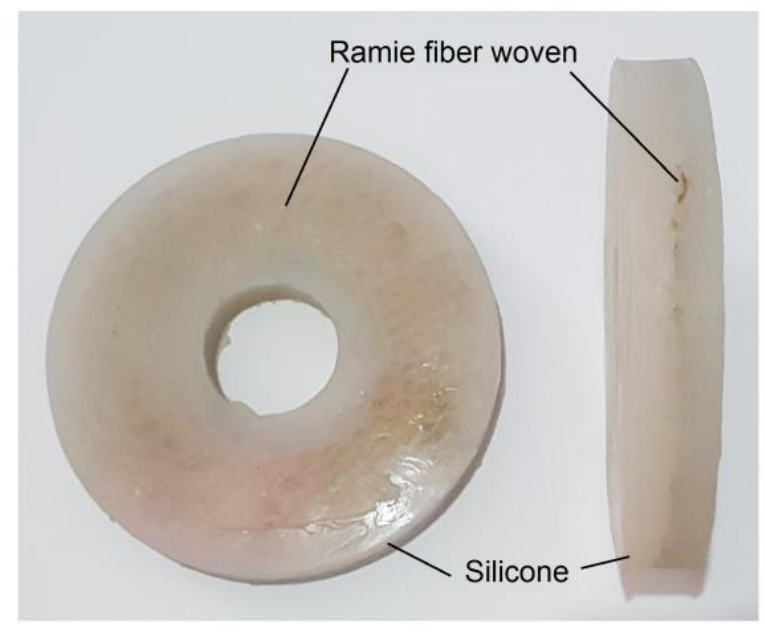

(a)

(b)

Figure 6. A sample of the silicone rubber gasket filled with a single layer of ramie fiber woven (a) top view and; (b) side view.

Before the gasket manufacturing process, the ramie fiber woven laid in the oven at temperature of $80^{\circ} \mathrm{C}$ for around 10 minutes. This process is required to remove moisture which may deteriorate the gasket properties. The gasket in the research consists of four different types is shown in Table 4.

Table 4. Silicon rubber gasket types.

\begin{tabular}{clcc}
\hline \multirow{2}{*}{ No } & \multicolumn{1}{c}{ Type of gasket } & \multicolumn{2}{c}{ Average Mass (gram) } \\
\cline { 3 - 4 } & & Silicone & Ramie \\
\hline 1 & Pure silicone & 100.2 & 0 \\
2 & Silicone with single layer ramie woven & 97.1 & 3.1 \\
3 & Silicone with double layer ramie woven & 94.1 & 6.2 \\
4 & Silicone with triple layer ramie woven & 91.1 & 9.2 \\
\hline
\end{tabular}

\section{Gasket Compression Test}

The gasket samples were tested in the universal testing machine SHIMADZU AGS-20kNX which has maximum capacity of $20 \mathrm{kN}$ as shown in Figure 7. The test was performed to obtain the compressive property of the silicone rubber composite gaskets. The samples were compressed at the displacement rate of $10 \mathrm{~mm} / \mathrm{min}$ at a room temperature. The maximum vertical displacement of the loading board is $5.5 \mathrm{~mm}$, which is equal to around $36 \%$ of the initial gasket thickness. 


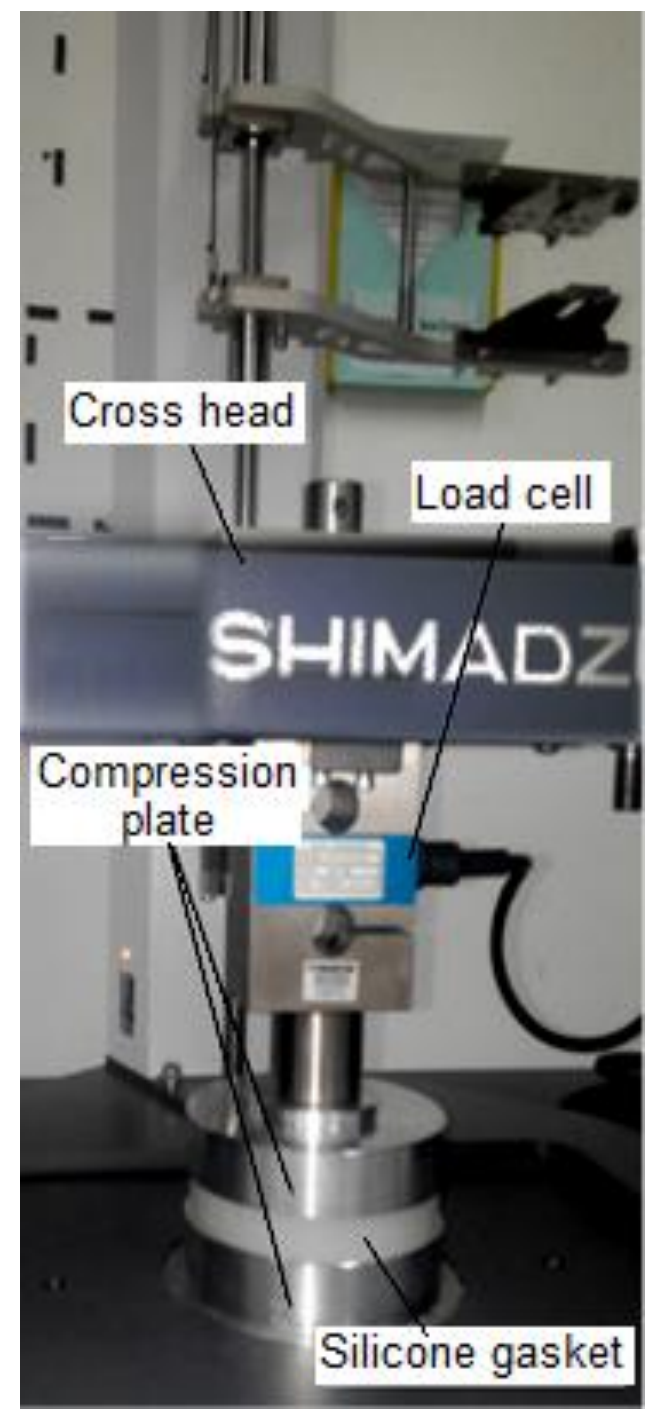

Figure 7. Gasket compression test in the universal testing machine Shimadzu.

\section{Water Pressure Experimental Set-Up}

The gasket and flanges were assembled then located in the supporting fixture and the connecting hose is attached securely to the water pressure pump outlet and to the upper flange inlet as shown in Figure 8. 


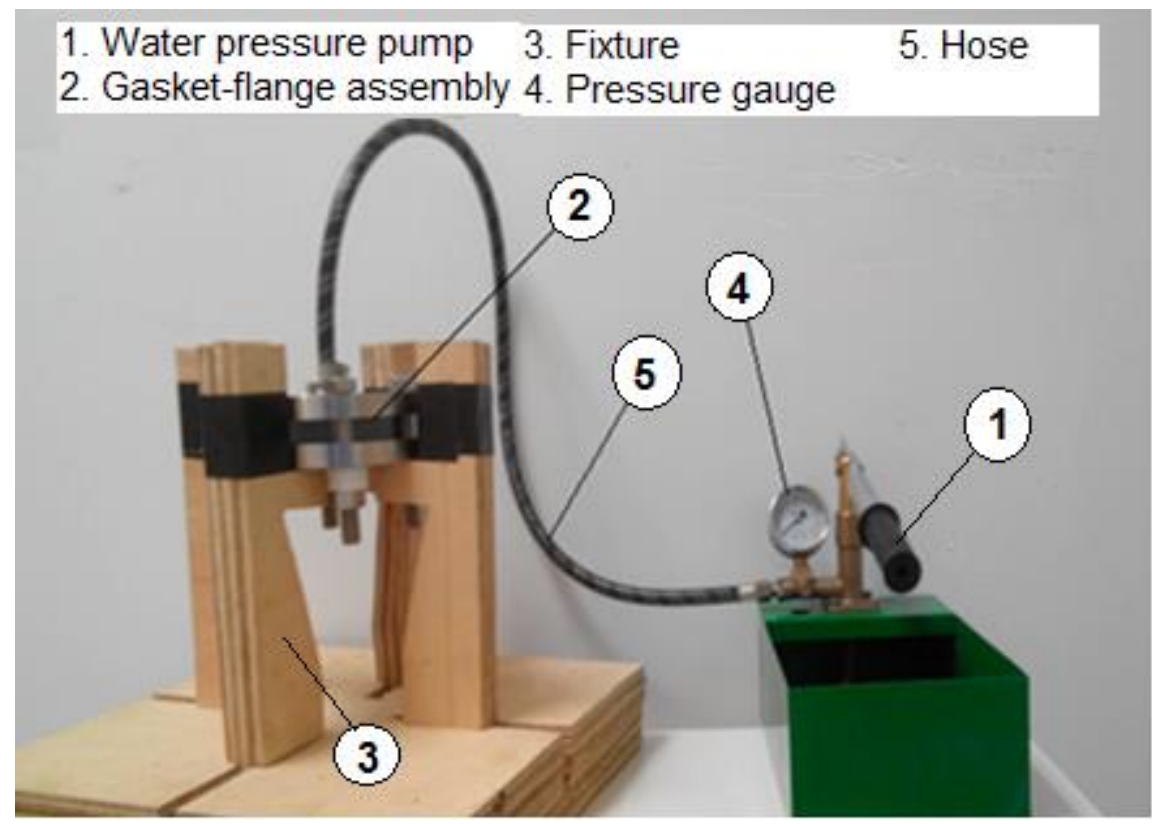

Figure 8. Water pressure leak test installation.

The bolts then tightened using an adjustable torque wrench with initial torque of 8 N.m. After the water leak test for this initial torque, the torque then increased at 12 N.m, 16 N.m and 20 N.m consecutively.

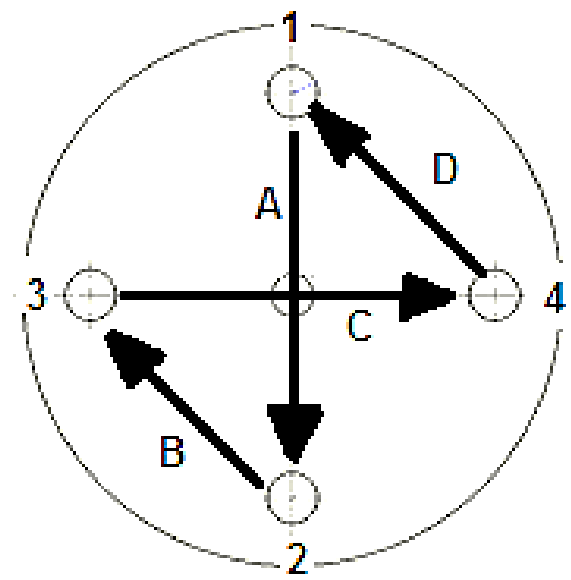

Figure 9. Bolts tightening sequence method.

Figure 9 shows the bolts tightening sequence method to obtain equal torque between every bolt and uniformly distributed stresses on the gasket surface. The tightening process sequence is $1-2-3-4$ and this process was performed several times until all of the bolts experienced equal value as defined in the torque wrench. 


\section{Water Pressure Test Procedure}

In this experiment, the sealing performance of the gaskets is evaluated based only on the evidence of the fluid leaks around the gasket-flange assembly while the leak quantity and leak rates of the fluid are neglected.

The fluid used in the experiment is water and the water pressure pump was used to provide an internal pressure until around $1 \mathrm{MPa}$. First the gasket was installed in the water pressure test rig then the torque applied at certain value i.e. 8 N.m, 12 N.m, 16 N.m and 20 N.m consecutively. The fluid pressure then applied by pumping the water pump until the fluid leaking detected and the pressure gauge drops rapidly. Every sample of the gasket (3 samples for each type) was observed and the maximum pressure value just before leaking occurred was recorded.

\section{RESULTS AND DISCUSSION}

\section{Gasket Compression Test}

Figure 10 shows the compressive responses of the pure silicone rubber gasket and silicone rubber composite gaskets filled with ramie fiber obtained from the universal testing machine SHIMADZU. The energy absorption capacity per unit volume, $\mathrm{W}_{\mathrm{v}}$ of the gasket can be defined from the total area under the stress-strain curve.

$$
\mathrm{W}_{\mathrm{v}}=\int \sigma \varepsilon d \varepsilon
$$

For the silicon rubber composite gasket filled with ramie fiber, the energy absorption can be defined as:

$$
\mathrm{W}_{\mathrm{c}}=\int \sigma_{s} \varepsilon_{s} d \varepsilon_{s}+\sigma_{r} \varepsilon_{r} d \varepsilon_{r}+\sigma_{i} \varepsilon_{i} d \varepsilon_{i}
$$

where the subscript $\mathrm{c}$ refers to composite gasket, $\mathrm{s}$ indicates the silicon rubber, subscript $\mathrm{r}$ indicates the ramie natural fibers and $i$ indicates the interface between the ramie and the silicone rubber.

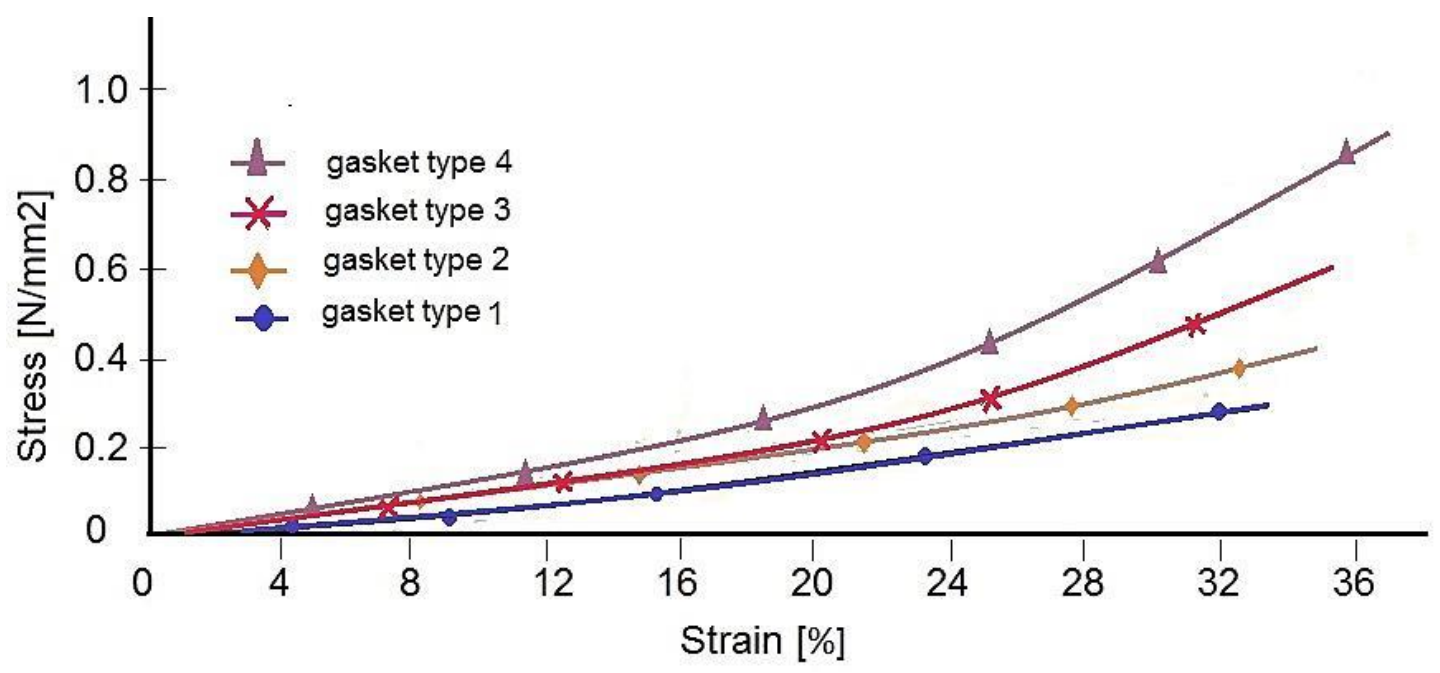

Figure 10. Compression test result for 4 different types of gasket.

It can be seen that the 3 types of gasket filled with fiber woven produce nearly the same curves while the pure silicone gasket produces almost linear curves. The pure silicone gasket 
(type 1) experienced lowest compressive stress and the gasket filled with 3 layers of woven ramie fiber (type 4) experienced highest compressive stress. Comparing the 3 composite gaskets filled with ramie fiber (type 2, 3 and 4), the stress level of the type 4 around tripled of the stress level of type 2 and the stress level of type 3 almost doubled compared to the type 2. The compressive stress increment from the test relates with the increasing stress at the interface between the silicon and the ramie fiber woven.

It can be seen also that the energy absorption capacity per unit volume of the type 4 (silicone gasket with 3 layers of the ramie fiber woven) gasket has been improved significantly compared to the type 1 (pure silicone gasket) as well as with the type 2 (silicone gasket with 1 layers of the ramie fiber woven) and with the type 3 (silicone gasket with 2 layers of the ramie fiber woven).

From this experiment, it can be concluded that the existence of the ramie woven increases the compressive stress of the silicon rubber composite gasket. This result shows a good agreement with the previous results produced by Yang et.al [3] and Yin et al. [4].

\section{Water Pressure Test Result}

Figure 11 to Figure 15 present data obtained from the water pressure leak test. The pressure value presented here shows the condition where leaks occur at a certain torque from 8 N.m to 20 N.m. The data presented are taken from 3 samples/gaskets for each type of gasket.

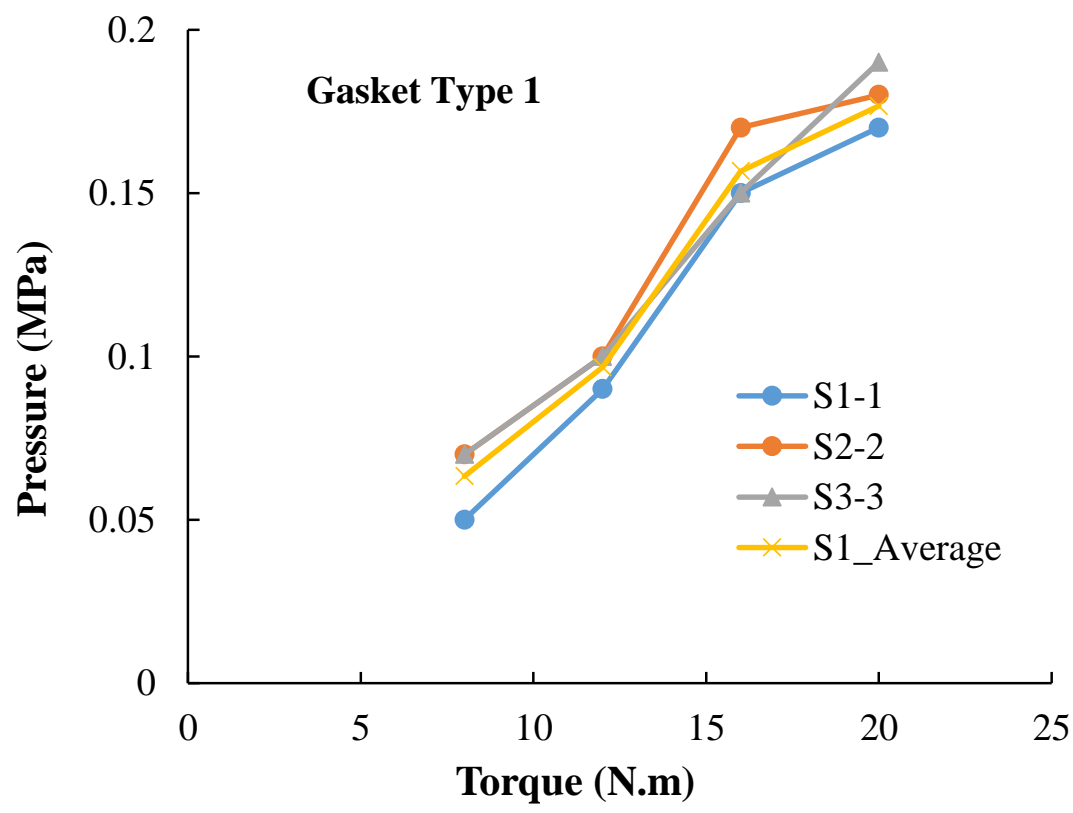

Figure 11. Water pressure test result for the gasket type 1.

Figure 11 shows the experimental result for the gasket type 1 (pure silicone rubber gaskets) for the three samples (S1-1 to S1-3). At the lowest torque (8 N.m) the gaskets experience leaking between $0.05 \mathrm{MPa}$ to $0.07 \mathrm{MPa}$ of the internal fluid pressure with the average value at $0.06 \mathrm{MPa}$. It can be seen from the graph that the maximum pressure that can be holding by the gaskets increased as the torque increased. For the maximum torque at 20 N.m the 
gaskets show the better sealing performance result where the maximum pressure before leaking achieved between $0.17 \mathrm{MPa}$ to $0.19 \mathrm{MPa}$ with average value at $0.18 \mathrm{MPa}$.

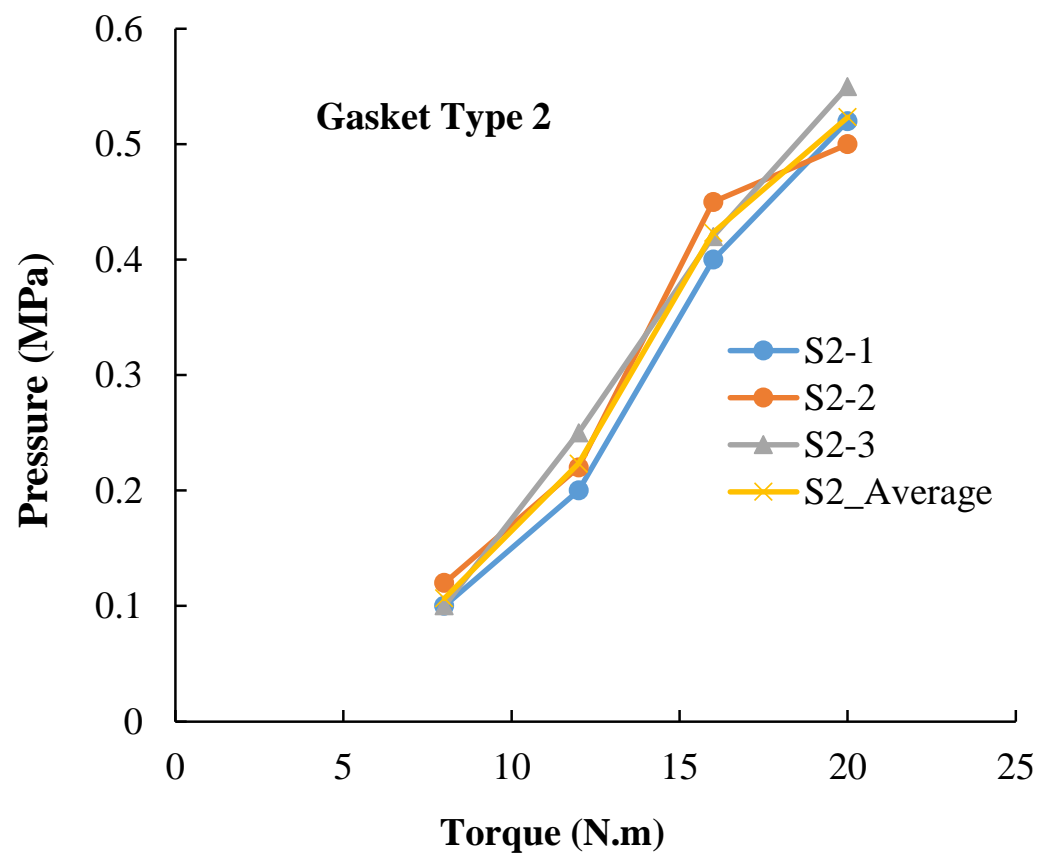

Figure 12. Water pressure test result for the gasket type 2.

Figure 12 depicts the experimental result for the three samples of the gasket type 2 (S2-1 to $\mathrm{S} 2-3)$. At the lowest torque $(8 \mathrm{~N} . \mathrm{m})$ the gaskets experience leaking at $0.10 \mathrm{MPa}, 0.12 \mathrm{MPa}$ and $0.10 \mathrm{MPa}$ for the sample S2-1, S2-2 and S2-3 respectively, with the average value at 0.11 $\mathrm{MPa}$. At the maximum torque of $20 \mathrm{~N} . \mathrm{m}$ the gaskets show the higher sealing performance result with the maximum pressure before leaking at around $0.50 \mathrm{MPa}$ to $0.55 \mathrm{MPa}$ with average value at $0.52 \mathrm{MPa}$. Comparing with the gasket type 1 , the sealing performance of the gasket type 2 increased significantly at higher torque. 


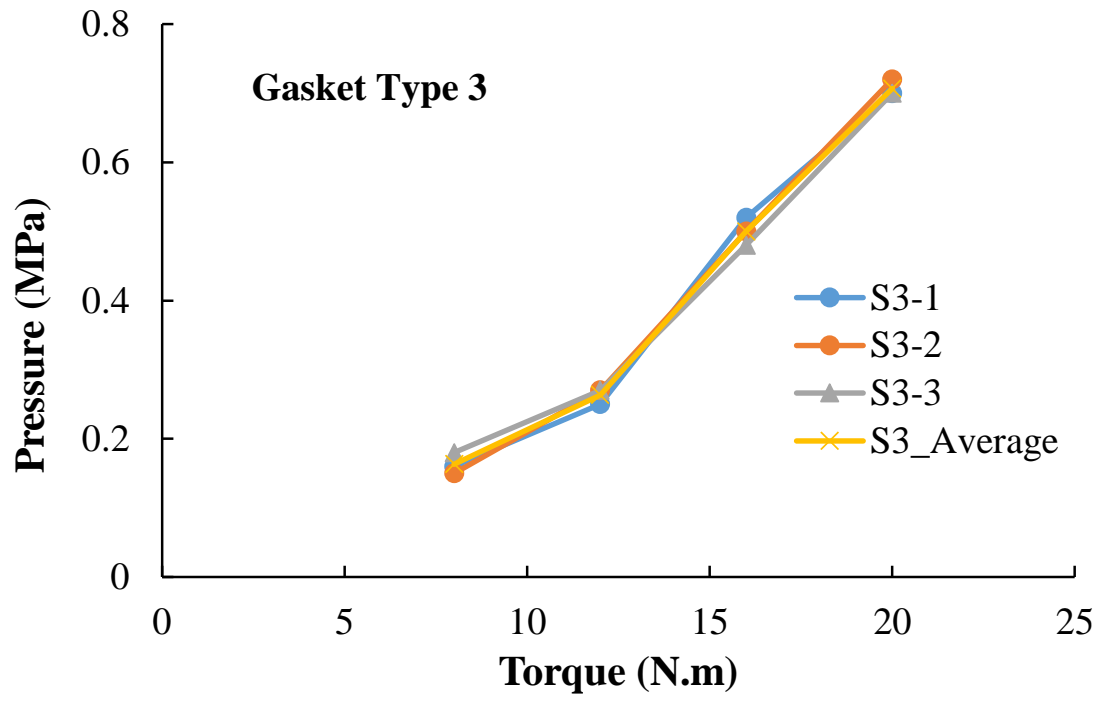

Figure 13. Water pressure test result for the gasket type 3.

Figure 13 illustrates the experimental result for the three samples of the gasket type 3 (silicone rubber composite gaskets with 2 layers of ramie woven) for the (S3-1 to S3-3). At the lowest torque $(8 \mathrm{~N} . \mathrm{m})$ the gaskets experience leaking at $0.16 \mathrm{MPa}, 0.15 \mathrm{MPa}$ and 0.18 MPa for the sample S3-1, S3-2 and S3-3 respectively, with the average value at $0.16 \mathrm{MPa}$. At the maximum torque of $20 \mathrm{~N} . \mathrm{m}$ the gaskets show the better sealing performance result with the maximum pressure before leaking achieved the average value at $0.71 \mathrm{MPa}$. Comparing with the gasket type 2, the sealing performance of the gasket type 3 increased at around $0.2 \mathrm{MPa}$ especially at the torque of $20 \mathrm{~N} . \mathrm{m}$.

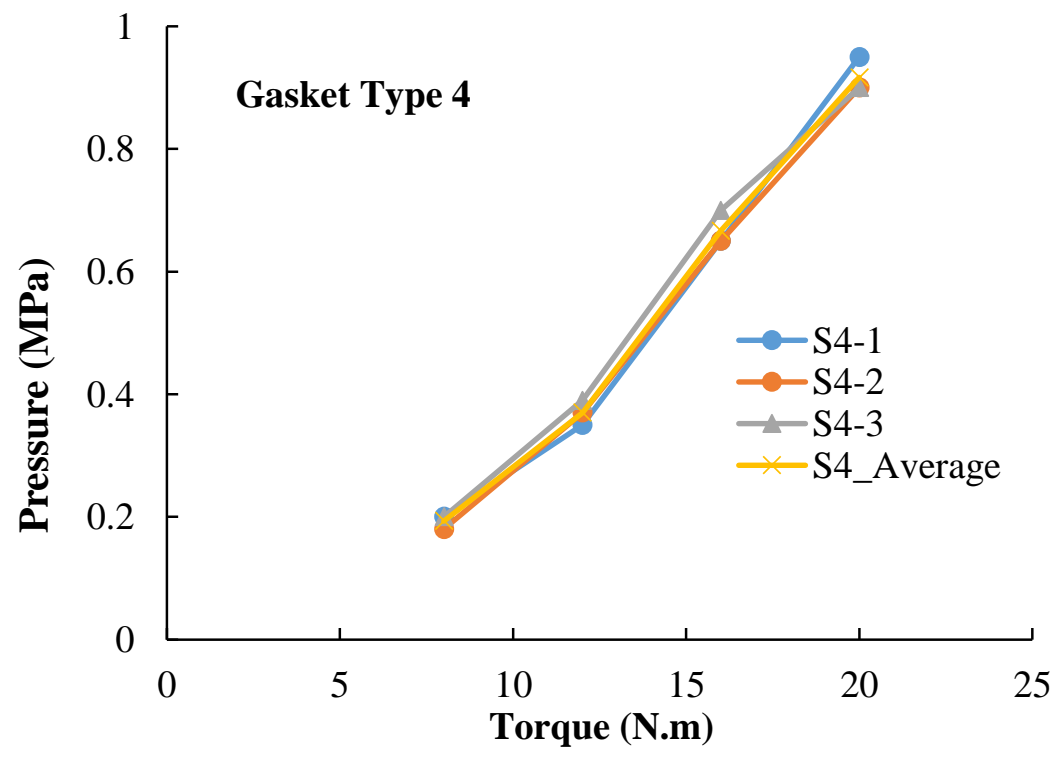

Figure 14. Water pressure test result for the gasket type 4. 
Figure 14 explains the experimental result for the gasket type 4 (silicone rubber composite gaskets with 3 layers of ramie woven) for the three samples (S4-1 to S4-3). At the torque (8 N.m) the gaskets experience leaking between $0.18 \mathrm{MPa}$ to $0.20 \mathrm{MPa}$ of the internal fluid pressure with the average value at $0.19 \mathrm{MPa}$. For the maximum torque at $20 \mathrm{~N} . \mathrm{m}$ the gaskets show the best sealing performance result where the maximum pressure before fluid leaking achieved the highest value at the average of $0.92 \mathrm{MPa}$.

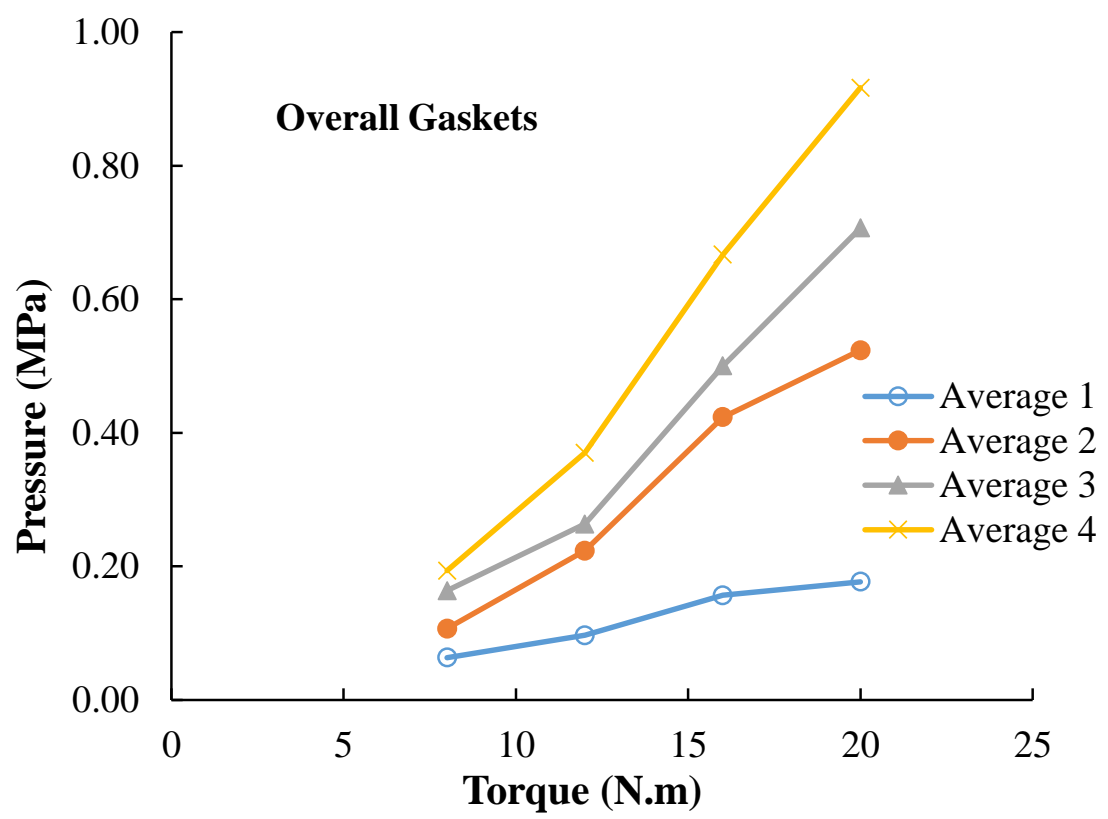

Figure 15. Water pressure test result for all gaskets.

Figure 15 explains the experimental result for the overall gaskets (gasket type 1 to gasket type 4). The results show that in the gasket type 1, which is a pure silicone gasket (without ramie fiber woven), the leak occurred at the lowest fluid pressure around $0.06 \mathrm{MPa}$ with the torque at $8 \mathrm{~N}$.m while the gasket type 4 indicates the highest fluid pressure at around 0.20 $\mathrm{MPa}$ at the same torque. When the torque increased the leak occurred at higher fluid pressure with the maximum pressure of $0.17 \mathrm{MPa}$ at $20 \mathrm{~N} . \mathrm{m}$ of the torque for the gasket type 1 and $0.90 \mathrm{MPa}$ for the gasket type 4.

In the gasket application, the bolts provide torsions which then converted as tightening forces resulting contact stresses between contact surfaces (i.e. between the lower flange surface and the lower surface of the gasket and between the upper flange surface with the upper surface of the gasket). It can be understood that as the torque increases the contact stress between the gasket and flanges also increases. It can be concluded also that the sealing performance of the gasket increases as the torque increases. These results agree with the results from previous researchers $[4,14-15,19-22]$ which stated that the sealing performance of the gasket increases as the contact stresses increase.

It can also be seen clearly that the sealing performance of the gasket increases with the number of the ramie woven layer. Comparing the pure silicone gasket (the gasket type 1) and the composite gasket with 3 layers of ramie woven, the maximum fluid pressure that can be hold is around 3 times at torque of $8 \mathrm{~N} . \mathrm{m}$ and more than 5 times at the maximum torque (20 N.m). 
Observing the sealing performance of the silicone gasket filled with ramie fiber woven only (type 2, 3 and 4), it can be seen that the leaks occurred at a higher value of the internal fluid pressure comparing with the pure silicone gasket. Focusing only to the silicone gaskets filled with the ramie woven, the leak occurred at $0.1 \mathrm{MPa}$ on the gaskets type 2 and increased almost 1.5 times in the gaskets type 3 and more 2 folds in the gaskets type 4 . In the highest torque value, the leak of the gasket with the ramie woven occurred at fluid pressure of $0.52 \mathrm{MPa}$ on the gaskets type 2 and in the gaskets type 4 the leak occurs at a fluid pressure of $0.95 \mathrm{MPa}$, which is almost 2 times of the gaskets type 2 . It can be concluded that the ramie fiber woven improved the sealing performance of the silicon rubber composite gasket.

\section{CONCLUSION}

In this paper, we discuss the sealing performance of a novel silicone rubber composite gasket made of the acetic silicone rubber filled with the ramie fiber woven. The 4 samples of gaskets (pure silicone rubber gaskets, silicone rubber gaskets with 1,2 and 3 layers of the ramie fiber woven) have been produced and tested. The initial compression tests for the gaskets showed that the stress level increased as the number of the ramie woven layer increased. Comparing with the pure silicone rubber gaskets, the silicone rubber filled with the ramie fiber gaskets indicate a significant increment which is almost 5 times on the gasket type 4 (silicone rubber composite gaskets with 3 layers of ramie fiber woven). The sealing performances of the gaskets also show similar responses. The pure silicon rubber gaskets only capable to hold the maximum pressure at $0.2 \mathrm{MPa}$ while the silicon rubber composite gaskets until $0.9 \mathrm{MPa}$ at 20 N.m of torque which is almost 5 times comparing with the pure silicone rubber gasket. The results show that the sealing performance of the silicone gasket can be improved by increasing the ramie woven layer.

\section{ACKNOWLEDGEMENT}

The authors would like to thank the Brawijaya University and the Universiti Teknikal Malaysia Melaka for the continuous support of this research project.

\section{REFERENCES}

[1] Persson BNJ, Yang C. Theory of the leak-rate of seals. Journal of Physics Condensed Matter. 2008;20(31):1-11.

[2] Flitney R. Seals and sealing handbook. $5^{\text {th }}$ Edition. Elsevier Science. 2007.

[3] Yang H, Yao XF, Ke YC, Ma YJ, Liu YH. Constitutive behaviors and mechanical characterizations of fabric reinforced rubber composites. Composite Structures. 2016;152:117-123.

[4] Yin S, Ma L, Wu LZ. Carbon fiber composite lattice structure filled with silicone rubber. Procedia Engineering. 2011;10:3191-3194. 
[5] Wen J, Li Y, Zuo Y, Zhou G, Li J, Jiang L, Xu W. Preparation and characterization of nano-hydroxyapatite/silicone rubber composite. Materials Letters. 2008;62(19):3307-3309.

[6] Wang L, Huang R, Zhou B, Zhang Y, Dong Y. Carbon fibers modified with siliconee peroxide containing vinyl groups for silicone rubber reinforcement. Materials Letters. 2016;176:38-41.

[7] Meunier L, Chagnon G, Favier D, Orgéas L, Vacher P. Mechanical experimental characterisation and numerical modelling of an unfilled silicone rubber. Polymer Testing. 2008;27(6):765-777.

[8] Saba NMT, Paridah A, Jawaid M. Mechanical properties of kenaf fibre reinforced polymer composite. Construction and Building Materials. 2015;76: 87-96.

[9] Jiang H, Li B, Zhao B, Sun Q, Gao C, Chen L. Evaluation of aging process of silicone rubber composite insulators with photothermal radiometry. Journal of Physics D: Applied Physics. 2018;51(42):1-9.

[10] Mishra RM, Rai JSP. Polyetherimide (pei) / silicone rubber composite reinforced with nanosilica particles. International Journal of Scientific \& Technology Research. 2016;(5)3:176-180.

[11] Jawaid, Khalil A. Cellulosic fibre reinforced polymer hybrid composites: a review. Carbohydrate Polymers. 2011;(86)1:1-18.

[12] Noshirwaan A, Ramachandran M, Krishna KG, Raichurkar PP. Review on various gaskets based on the materials, their characteristics and applications. International Journal on Textile Engineering and Processes. 2017;(3)1:12-18.

[13] Layth M, Ansari MNM, Grace P, Jawaid M, Islam SM. A review on natural fiber reinforced polymer composite and its applications. International Journal of Polymer Science. 2015:1-15.

[14] Lorenz B, Persson BNJ. Leak rate of seals: Comparison of theory with experiment. Europhysics Letters. 2009; 86(44006):1-6.

[15] Choiron MA, Purnowidodo A, Sealing performance of thin corrugated metal gasket. Applied Mechanics and Materials. 2015;789-790: 246-250.

[16] Zhou SM, Chen P, Shi Y. Analysis on sealing performance for a new type of rubber saddle-shaped sealing ring based on ABAQUS. $14^{\text {th }}$ International Conference on Pressure Vessel Technology. Procedia Engineering. 2015;130: 1000-1009.

[17] Zhou C, Chen G, Pengfei L. Finite element analysis of sealing performance of rubber d-ring seal in high-pressure hydrogen storage vessel. Journal of Failure Analysis and Prevention. 2018;18(4):846-855.

[18] Wei L, Xiong Q, Xiaomei L, Han X, Zhang F, Hong J. Finite element analysis of the o-ring squeezed into the sealing clearance based on ABAQUS. Proceeding AsiaPacific Engineering and Technology Conference. 2017:537-545.

[19] Nurhadiyanto D, Choiron MA, Kaminishi K, Haruyama S. Optimization of new 25asize metal gasket design based on contact width considering forming and contact stress effect. World Academy of Science, Engineering and Technology. 2012;63:661665.

[20] Nurhadiyanto D, Haruyama S, Kaminishi K, Karohika IGM, Mujiyono. Contact stress and contact width analysis of corrugated metal gasket. Applied Mechanics and Materials. 2015;765-769. 
[21] Karohika IGM, Haruyama S, Kaminishi K, Oktavianty O, Nurhadiyanto D. Analysis of contact width and contact stress of three-layer corrugated metal gasket. International Journal of Mechanical and Mechatronics Engineering. 2017;11(4):870879.

[22] Choiron MA, Haruyama S, Kaminishi K. Simulation and experimentation on the contact width of new metal gasket for asbestos substitution. International Journal of Aerospace and Mechanical Engineering. 2011;5(4):283-287.

[23] Nordin MNA, Sakamoto, Azhari KH, Goda K, Okamoto M, Ito H and Endo T. Tensile and impact properties of pulverized oil palm fiber reinforced polypropylene composites: A comparison study with wood fiber reinforced polypropylene composites. Journal of Mechanical Engineering and Sciences. 2018;12(4): 41914202.

[24] Ahsan Q, Carron TSS, and Mustafa Z. On the use of nano fibrillated kenaf cellulose fiber as reinforcement in polylactic acid biocomposites. Journal of Mechanical Engineering and Sciences. 2019;13(2):4970-4988.

[25] Taufik RS, Nurul Farah Adibah M, Muhamad MR and Hasib H. Feasibility study of natural fiber composite material for engineering application. Journal of Mechanical Engineering and Sciences. 2014;6:940-948.

[26] AISI 304 Stainless Steel. ASM Aerospace Specification Metals Inc.. Retrieved from http://asm.matweb.com/search/SpecificMaterial.asp?bassnum=mq304a. 2018.

[27] Acetic silicone general purpose (SL212). Technical Data Sheet. Henkel AG \& Co. 2012. 